\title{
Prevalence and factors associated with intimate partner violence among the adolescent girls and young women in South Africa: findings the 2017 population based cross-sectional survey
}

Jacqueline Mthembu ${ }^{1,2^{*}}$, Musawenkosi Mabaso ${ }^{3}$, Sarah Reis ${ }^{4}$, Khangelani Zuma ${ }^{1,5}$ and Nompumelelo Zungu ${ }^{1,6}$

\begin{abstract}
Background: Evidence indicate that intimate partner violence (IPV) is disturbingly high among South African adolescent girls and young women (AGYW). Understanding prevalence and risk factors for IPV among these emerging adults is critical for developing appropriate interventions to prevent adverse health outcomes later in life. This study investigates the prevalence and factors associated with lifetime physical IPV experience among AGYW, aged 15-24 years, using the South African national HIV prevalence, incidence, behaviour and communication survey conducted in 2017.
\end{abstract}

Methods: The data used in this secondary analysis was obtained from a cross-sectional, population-based household survey data, conducted using a multi-stage stratified random cluster sampling approach. Multivariate stepwise backward logistic regression modelling was used to determine factors associated with IPV.

Results: Of 716 AGYW that responded to the two commonly answered questions on IPV, 13.1\% (95\% Cl: 9.6-17.6) indicated that they experienced IPV. The odds of reporting experiences of IPV were significantly lower among AGYW residing in high SES households [AOR $=0.09$ (95\% Cl: 0.02-0.47), $p=0.004$ ] than low SES households, and those residing in rural informal/tribal areas $[A O R=0.01$ (95\% Cl: $0.00-0.22), p=0.004$ ] than urban areas. AGYW experiencing IPV had higher odds of reporting psychological distress compared to their counterparts $[\mathrm{AOR}=4.37$ (95\% Cl, 0.97-19.72), $p=0.054]$.

Conclusion: The findings highlight the need for targeted structural and psychosocial interventions in low SES households and especially in urban areas.

Keywords: Intimate partner violence, Adolescent girls and young women, South Africa

\footnotetext{
* Correspondence: jmthembu@hsrc.ac.za

${ }^{1}$ Human and Social Capabilities Division, Human Sciences Research Council,

Pretoria, South Africa

${ }^{2}$ University of California, Los Angeles, USA

Full list of author information is available at the end of the article
}

(c) The Author(s). 2021 Open Access This article is licensed under a Creative Commons Attribution 4.0 International License, which permits use, sharing, adaptation, distribution and reproduction in any medium or format, as long as you give appropriate credit to the original author(s) and the source, provide a link to the Creative Commons licence, and indicate if changes were made. The images or other third party material in this article are included in the article's Creative Commons licence, unless indicated otherwise in a credit line to the material. If material is not included in the article's Creative Commons licence and your intended use is not permitted by statutory regulation or exceeds the permitted use, you will need to obtain permission directly from the copyright holder. To view a copy of this licence, visit http://creativecommons.org/licenses/by/4.0/. The Creative Commons Public Domain Dedication waiver (http://creativecommons.org/publicdomain/zero/1.0/) applies to the data made available in this article, unless otherwise stated in a credit line to the data. 


\section{Background}

Intimate partner violence (IPV) experienced by women is a global public health concern. IPV refers to any act of physical and sexual aggression or harm, sexual coercion, controlling behaviours, psychological/emotional abuse within an intimate relationship by a current or former partner/spouse [1]. Despite numerous intervention efforts over the last decade, the burden of IPV continues to grow [2]. The World Health Organization report global IPV estimates of just over $30 \%$ among everpartnered women with similar rates estimated across sub-Saharan Africa [3]. South Africa is among the countries with the highest rates of IPV experienced by women in the world [4]. A growing body of research show that IPV among adolescent girls and young women (AGYW) is receiving increased attention due to its widespread nature and severe health consequences [5].

The negative health consequences of IPV (childhood/ lifetime/past year experience) include adverse physical health outcomes (injury and death), poor mental health (depression and anxiety), sexual health risks (sexually transmitted infections including HIV), and reproductive health risks (unwanted pregnancy and abortion) [6-9]. IPV also leads to negative social consequences such as substance abuse which include alcohol misuse and drug use [9]. To inform IPV prevention efforts it is important to measure and understand factors associated with experiences of IPV.

Current evidence shows that factors associated with IPV (childhood/lifetime/past year experience) include low educational status, low socio-economic status, and gender inequalities including substance misuse by either the woman or her partner $[10,11]$. The foremost psychological consequences of IPV include depression, post-traumatic stress disorder, and substance use disorders. Women with histories of IPV have been shown to suffer subsyndromal symptoms of mental health disorders, such as psychological distress symptoms [9-11]. Conversely, others have shown that women who experienced psychological distress were at increased risk IPV $[9,11]$. This has been attributed to neurocognitive impairments that interfere with ability to evaluate danger, social skill and problem-solving deficits, stigma, and social isolation [9]. Other factors associated with IPV include sexual risk factors such as age disparate sexual relationships, transactional sex, and having multiple sexual partners [11]. IPV has also been associated with unequal gender power dynamics in relationships emanating from gender inequitable and harmful masculinities [7, 9, 12-15].

The South African Government in response to the growing scourge of IPV has pledged to address violence against women its causes and consequences through collection of relevant data in order to inform prevention activities [16]. Despite these progressive reforms, underreporting remains a challenge and the Government's response remains sporadic and unsatisfactory. Improved understanding of the burden of IPV and associated factor risk is vital to achieve a more complete picture of the true burden and its effect within populations in order to inform ongoing prevention efforts. However, little evidence exists on population-based prevalence and risk factors for IPV in South Africa. The aim of this paper was to investigate the prevalence and factors associated with lifetime physical IPV experience among the AGYW using a population-based household survey conducted in 2017 in South Africa.

\section{Methods}

Data source

The data used in this secondary analysis was obtained from the South African national HIV prevalence, incidence, behaviour and communication survey conducted in 2017. This is a cross-sectional, population-based household survey conducted using a multi-stage stratified random cluster sampling approach [17]. Basically, a total of 1000 small area layers (SALs) were sampled using the 2015 national population sampling frame of 103,000 SALs developed by Statistics South Africa [4]. The selection of SALs was stratified by province, locality type (urban formal, rural formal, and rural informal/tribal areas) and race groups in urban areas. A total of 15 visiting points (VPs) were randomly selected from each of the 1000 SALs, targeting 15,000 VPs. Of these, 12,435 (82.9\%) VPs were approached. Among these VPs, 11,776 (94.7\%) were valid and household response rate of $82.2 \%$ was achieved from the valid VPs. All members of selected households were eligible to participate in the survey.

Survey instruments included a household questionnaire and three age-appropriate questionnaires administered to consenting individuals. Questionnaire data were collected digitally using electronic tablets. For those younger than 18 years of age, consent was given by parents/guardians and assent by the participant. The interview instruments solicited information among others on demographic, behavioural, social and health characteristics of the sample. Data were weighted to account for the differential selection probabilities at the enumeration areas, households, and individual levels. The weights were benchmarked to the Statistics South Africa national midyear population estimates by age, race, sex and province to ensure that the data was nationally representative. The focus of the present paper was on AGYW 1524 years who responded to the questions on experiences of IPV, and only female data for this age group was extracted from the national dataset. 
Table 1 Demographic, behavioural, social and health related characteristics of the study sample, adolescent girls and young women (15-24 years), South Africa

\begin{tabular}{|c|c|c|}
\hline Variables & $\mathrm{N}^{\mathrm{a}}$ & $\%$ \\
\hline \multicolumn{3}{|l|}{ Age group in years } \\
\hline $15-19$ & 224 & 26.4 \\
\hline $20-24$ & 492 & 73.6 \\
\hline \multicolumn{3}{|l|}{ Race groups } \\
\hline African & 594 & 87.9 \\
\hline other & 122 & 12.1 \\
\hline \multicolumn{3}{|l|}{ Marital status } \\
\hline Married & 32 & 5.8 \\
\hline Never married & 681 & 94.2 \\
\hline \multicolumn{3}{|l|}{ Education level } \\
\hline No education/Primary & 34 & 6.2 \\
\hline Secondary & 356 & 80.2 \\
\hline Tertiary & 38 & 13.6 \\
\hline \multicolumn{3}{|l|}{ Employment status } \\
\hline Not employed & 616 & 86.1 \\
\hline Employed & 95 & 13.9 \\
\hline \multicolumn{3}{|l|}{ Asset based SES ${ }^{b}$} \\
\hline LOW SES & 374 & 54.6 \\
\hline HIGH SES & 286 & 45.4 \\
\hline \multicolumn{3}{|l|}{ Locality type } \\
\hline Urban & 392 & 64.6 \\
\hline Rural informal (tribal areas) & 253 & 30.0 \\
\hline Rural (farms) & 71 & 5.4 \\
\hline \multicolumn{3}{|l|}{ AUDIT score ${ }^{c}$} \\
\hline Abstainers & 477 & 73.1 \\
\hline Low risk drinkers (1-7) & 101 & 19.6 \\
\hline High risk drinkers (8-19) & 46 & 5.6 \\
\hline Hazardous drinkers (20+) & 5 & 1.7 \\
\hline \multicolumn{3}{|l|}{ Orphanhood } \\
\hline Not orphan & 188 & 62.7 \\
\hline Orphan & 112 & 37.3 \\
\hline \multicolumn{3}{|l|}{ Psychological distress } \\
\hline Absent & 576 & 77.9 \\
\hline Present & 137 & 22.1 \\
\hline
\end{tabular}

${ }^{a}$ Subtotals do not all equal to the total (N) due to non-response and / or missing data, bsocio-economic status, (SES), calcohol risk score based on a questionnaire for Alcohol Use Disorder Identification Test (AUDIT)

\section{Measures}

\section{Primary outcome variable}

One adult member aged 15 years and older, from each household was randomly selected to participate in the IPV module deals with violence experienced in intimate relationships. Discretion and confidentiality were maintained during the survey to assure the privacy and safety of all respondents. Due to the sensitive nature of the subject responses to most of the questions were extremely low. Hence, the primary outcome measure lifetime physical IPV experience was based only on the commonly answered questions "Did your partner ever do any of the following things to you that could hurt you?

Question 1: Push you, shake you, or throw something at you? (Yes = 1 and $\mathrm{No}=2$ ).

Question 2: Slap you? (yes $=1$ and no $=2$ ).

The responses were coded and dichotomised to generate IPV as follows:

$\operatorname{IPV}(\mathrm{No}=0)$ if question $1=2$ and question $2=2$.

IPV $($ Yes $=1)$ if question $2=1$ and question $2=1$.

\section{Explanatory variables}

Explanatory measured included socio-demographic characteristics such as age (15-19 years and 20-24 years), race (Black Africans and other race groups, which included Whites,

Coloureds, and Indians/Asians), marital status (married and not married; which included divorced/separated and widowed/widow), educational level completed (no education, primary, secondary, and tertiary), employment status (not employed and employed), locality type (urban formal, rural informal, rural formal), and assetbased socio-economic status (SES) which was constructed using multiple correspondence analyses (MCA) based on questions on the availability of essential services and ownership of a range of household assets [18]. MCA is a data reduction technique for categorical data, which calculates a composite indicator score computed by adding up all the weighted responses. The predicted score for each household was used to compute five quintiles (1st lowest, 2nd lower, 3rd middle, 4th higher and 5th highest) representing a continuum of household SES from the poorest to the least poor. The quintiles were then dichotomized into low SES or poorest (lowest 3 quintiles) high SES or less-poor (highest 2 quintiles).

Other explanatory variables included behavioural, social and health related factors such as alcohol use was measured using the Alcohol Use Disorders Identification Test (AUDIT) risk score $(0=$ abstainers; $1-7=$ low-risk drinkers; 8-19 = high-risk drinkers; 20+=hazardous drinking) [19], which has been validated in South Africa [20], orphanhood (not orphan, orphan) and, Psychological distress was derived from the 10 item Kessler psychological distress scale (K10) [21]. The K10 scale appraises of items on how respondents felt during the previous 30 days on a 5 -point Likert scale $(1=$ never, $2=$ rarely, $3=$ some of the time, $4=$ most of the time, $5=$ all 
of the time). Cronbach's alpha (0.92) indicated a high level of internal consistency of the K10 scale. Raw scores were summed, and the scale was dichotomized into two categories with a total score $\leq 20$ for absence of psychological distress and $>20$ for presence of psychological distress.

\section{Statistical analysis}

Descriptive statistics was used to summarize the characteristics of the study sample, and differences between categorical variables was assessed using a Pearson chisquare test. Multivariate stepwise logistic regression analysis using a backward procedure was used to identify factors associated with IPV among AGYW. Probability for removal of variables in the model were set at $p$ values of 0.20 . Adjusted odds ratios (AORs) with 95\% confidence intervals $(\mathrm{CI})$ are reported, and p-values less than 0.05 were considered statistically significant. Coefficient plots were used to display the results of the final model. All statistical analysis was done in Stata version 15.0 software using "svy" commands to take into account the complex multilevel survey design (Stata Corporation, College Station, Texas, USA).

\section{Results}

\section{Characteristics of the study sample}

Table 1 describe the study sample. Most of the study participants were young women (20-24 years), Black African, never married, had secondary level education, and were unemployed.
More than a half AGYW resided in low SES households. Most resided in urban areas, were abstainers, were not orphans, and reported absence of psychological distress.

\section{Prevalence of IPV}

Of 716 AGYW that responded to the two commonly answered questions on IPV, 13.1\% (95\% CI: 9.6-17.6) indicated that they experienced lifetime physical IPV. Figure 1 shows that the prevalence of IPV was highest in the Gauteng province at $44.8 \%$ followed by KwaZulu-Natal and the Eastern Cape with prevalence at $13.3 \%$, respectively. Table 2 shows that the prevalence of lifetime physical IPV experience was significantly high among those not married, and those not orphaned. Even though not statistically significant, experiences of lifetime physical IPV was also higher among Black Africans, the unemployed, those from low SES households, and those with psychological distress.

\section{Factors associated with lifetime physical IPV among AGYW}

Figure 2 presents the multivariable model of factors associated with lifetime physical IPV experience among AGYW 15-24 years. The odds of reporting experiences of lifetime physical IPV were significantly lower among AGYW residing in high SES households compared to those in low SES households $[\mathrm{AOR}=0.09$ (95\% CI: $0.02-0.47), p=0.004]$, and those residing in rural

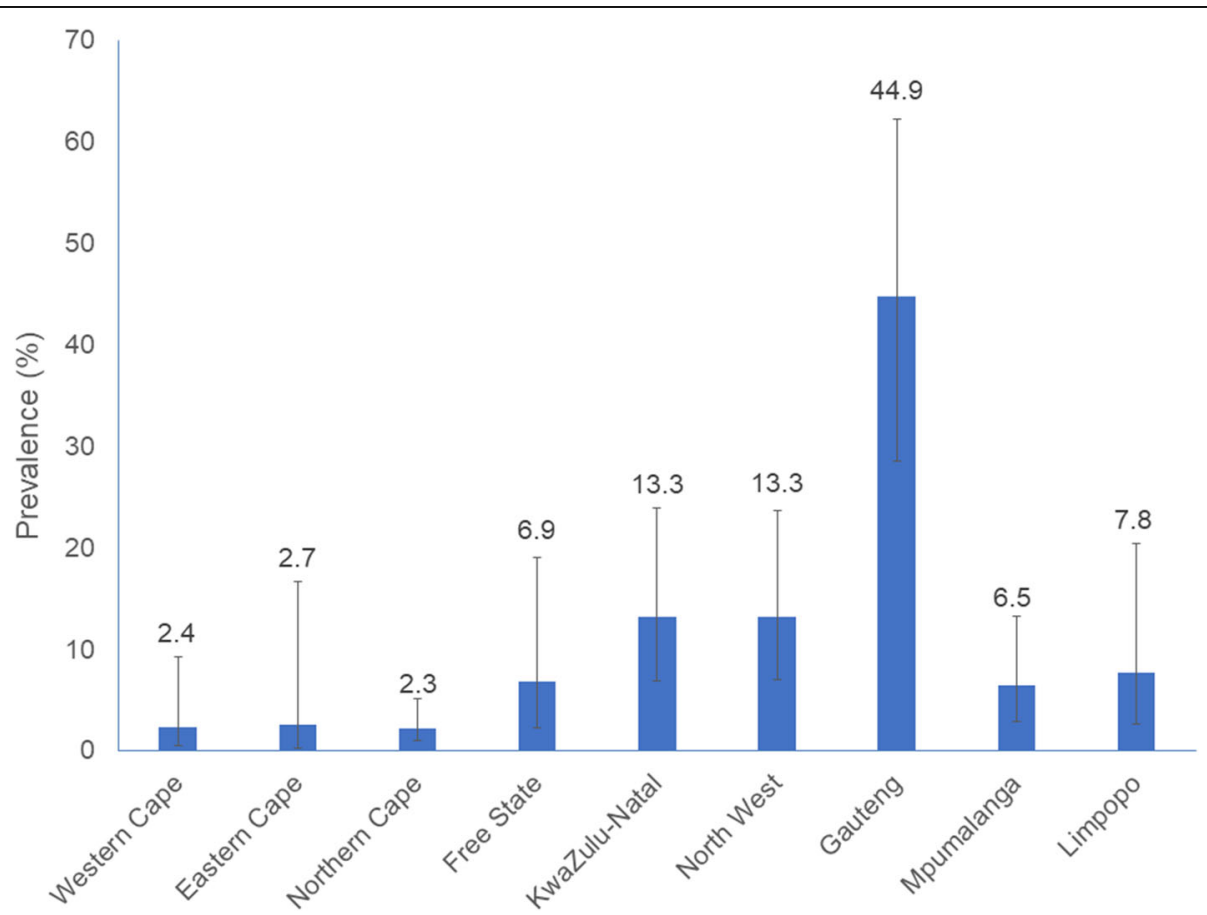

Fig. 1 Prevalence of lifetime intimate partners violence experience by province, South Africa, 2017 
Table 2 Prevalence of experience of lifetime physical IPV among adolescent girls and young women by demographic, behavioural, social and health related variables, South Africa 2017

\begin{tabular}{|c|c|c|c|c|}
\hline \multirow[t]{2}{*}{ Variables } & \multicolumn{4}{|c|}{ Intimate partner violence (IPV) } \\
\hline & $\mathrm{N}^{\mathrm{a}}$ & $\%$ & $95 \% \mathrm{Cl}$ & p-value \\
\hline \multicolumn{5}{|l|}{ Age groups in years } \\
\hline $15-19$ & 224 & 14.2 & $6.9-27.1$ & 0.766 \\
\hline $20-24$ & 492 & 12.7 & $9.1-17.4$ & - \\
\hline \multicolumn{5}{|l|}{ Race groups } \\
\hline African & 594 & 13.8 & $9.9-19.0$ & 0.091 \\
\hline other & 122 & 7.7 & $4.1-14.0$ & - \\
\hline \multicolumn{5}{|l|}{ Marital status } \\
\hline Married & 32 & 3.6 & $0.8-13.8$ & 0.039 \\
\hline Never married & 681 & 13.7 & $10.0-18.6$ & - \\
\hline \multicolumn{5}{|l|}{ Education level } \\
\hline No education/Primary & 34 & 17.0 & $6.7-36.8$ & 0.194 \\
\hline Secondary & 356 & 17.8 & $12.5-24.5$ & - \\
\hline Tertiary & 38 & 4.9 & $0.8-25.8$ & - \\
\hline \multicolumn{5}{|l|}{ Employment status } \\
\hline Not employed & 616 & 13.8 & $9.9-19.0$ & 0.223 \\
\hline Employed & 95 & 7.9 & $3.2-18.2$ & - \\
\hline \multicolumn{5}{|l|}{ Asset based SES ${ }^{b}$} \\
\hline LOW SES & 374 & 14.3 & $9.8-20.3$ & 0.464 \\
\hline HIGH SES & 286 & 10.9 & $5.7-19.9$ & - \\
\hline \multicolumn{5}{|l|}{ Locality type } \\
\hline Urban & 392 & 14.0 & $9.2-20.7$ & 0.580 \\
\hline Rural informal (tribal areas) & 253 & 10.8 & $6.6-16.9$ & - \\
\hline Rural (farm areas) & 71 & 14.8 & $7.1-28.2$ & - \\
\hline \multicolumn{5}{|l|}{ AUDIT score ${ }^{c}$} \\
\hline abstainers & 477 & 11.10 & $7.7-15.8$ & 0.523 \\
\hline low risk drinkers (1-7) & 101 & 15.2 & $7.9-27.2$ & - \\
\hline high risk drinkers (8-19) & 46 & 14.9 & $4.2-41.2$ & - \\
\hline hazardous drinkers $(20+)$ & 5 & 31.4 & $5.2-79.2$ & - \\
\hline \multicolumn{5}{|l|}{ Orphanhood } \\
\hline not orphan & 188 & 18.0 & $9.2-32.3$ & 0.037 \\
\hline orphan & 112 & 6.1 & $2.6-13.9$ & - \\
\hline \multicolumn{5}{|l|}{ Psychological distress } \\
\hline Absence & 576 & 11.9 & $8.5-16.3$ & 0.290 \\
\hline Presence & 137 & 17.9 & $8.8-32.9$ & \\
\hline
\end{tabular}

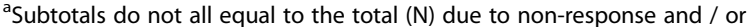

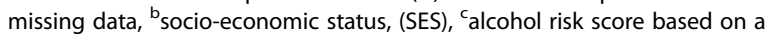
questionnaire for Alcohol Use Disorder Identification Test (AUDIT)

informal/tribal areas $[\mathrm{AOR}=0.01$ (95\% CI: $0.00-0.22)$, $\mathrm{p}=0.004]$ compared to urban areas. AGYW experiencing IPV had higher odds of reporting psychological distress compared to their counterparts $[\mathrm{AOR}=4.37(95 \%$ CI: 0.97-19.72), $p=0.054]$.

\section{Discussion}

This is the first nationally representative cross-sectional survey focusing on prevalence and risk factors for lifetime physical IPV experience, among AGYW in South Africa. This secondary data analysis revealed that nationally the prevalence of lifetime physical IPV experiences among AGYW was $13.1 \%$. This is lower than earlier provincial estimates reported in another study at 19.5 and $24.1 \%$ [4]. These low prevalence estimates could be due to the fact that 1) the national survey, unlike other IPV studies, focused on many other health related outcomes with a particular focus on HIV, and 2) only one household member was randomly selected to respond to IPV section of the questionnaire [17]. These observations highlight the need to prioritise IPV research especially among AGYW. The prevalence of lifetime physical IPV experience in this study varied with respect to a number of socio-demographic and socio-behavioural characteristics. Significant variations were between provinces with Gauteng reporting the highest IPV prevalence followed by KwaZulu-Natal and Eastern Cape provinces. These observations provide important clues for tailored and targeted approaches for improving IPV interventions.

In the final model lifetime physical IPV experiences was inversely associated with residing in high SES than low SES households. This probably reflects a cascade of interacting social vulnerabilities, which include limited access to social resources in low SES households which heightens exposure to IPV [22, 23]. In fact, evidence suggests that IPV can be concentrated in socialenvironments or settings with poverty and other dimensions of disadvantage $[22,23]$. This implies that preventive measures and social support measures for IPV victims should be tailored for and targeted at social vulnerabilities and social environmental contexts that put young women at risk of IPV.

In the current paper lifetime physical IPV experiences was also inversely associated with residing in rural than urban settings. Incongruent with these findings studies have shown that disadvantaged urban settings can exacerbate underlying gender-based power disparities, with young women subject to intensive gender-based harassment and a pervasive threat of sexual and physical violence $[24,25]$. Evidence suggests that adverse socioeconomic conditions influenced by early adversity and social hardship may prompt violence perpetration by men seeking to reclaim power prompting discord that leads to violence [26]. However, more research is needed for improved understand of the underlying processes of social hardship, social gender norms, masculine identity, and power dynamics within relationships where IPV is prevalent.

Furthermore, lifetime physical IPV experiences was significantly associated with psychological distress. Other 


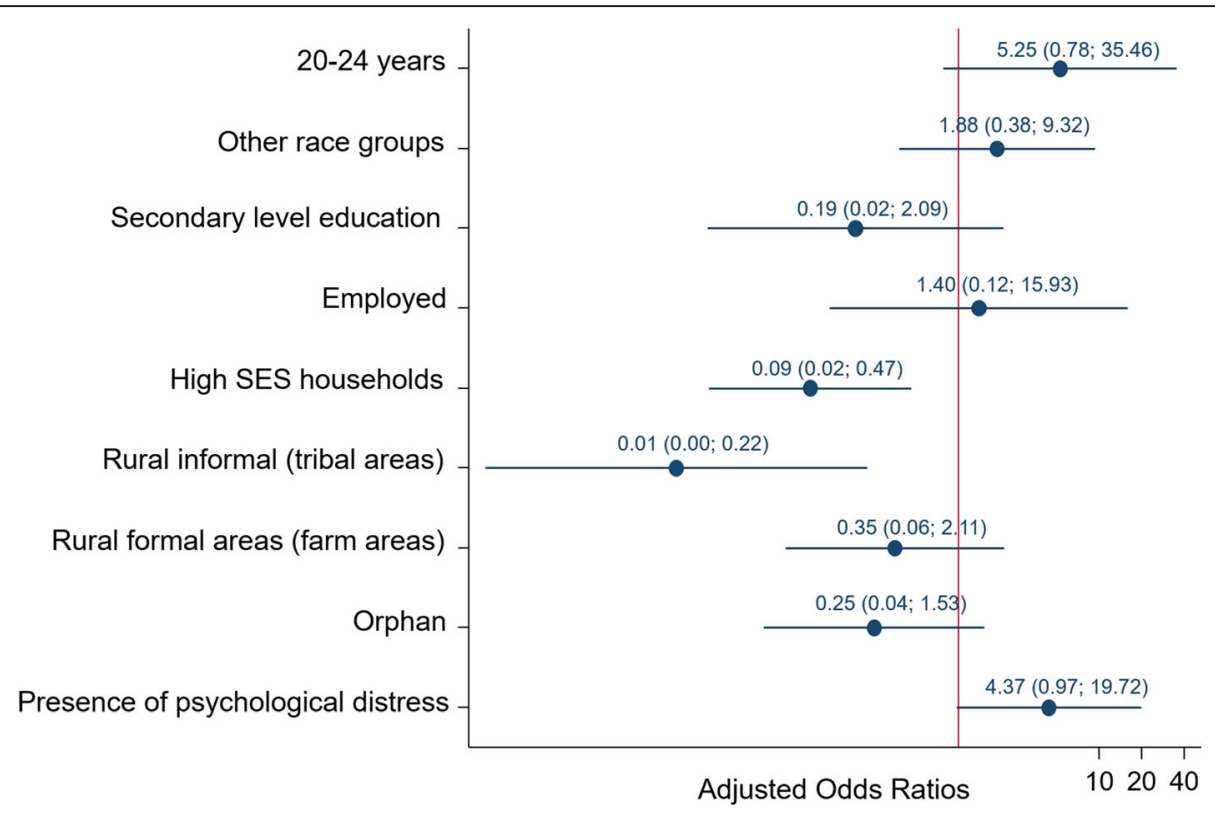

Fig. 2 Multivariate model of factors associated with lifetime physical IPV experience among adolescents and young women, South Africa, 2017

studies found that women experiencing physical IPV were likely to suffer from depression and anxiety indicative of psychological distress [27, 28]. Although the mechanisms underlying the relationship between IPV and psychological distress need to be better understood, it is possible that early trauma such as childhood/past exposure and/or social exposure IPV may be underlying causes and contribute to increased risk of psychological distress [29]. Posttraumatic stress disorder has been identified in women exposed to IPV along with comorbid symptoms such as depression, anxiety, suicidality and sleep disturbances $[8,30]$. It has been suggested that harm reduction interventions in young women can be archived through universal education which incorporates relationship health that educate and enquire about abusive behaviours and IPV particularly in reproductive and adolescent health settings [31-33].. In addition, schoolbased educational efforts targeting the youth should include information about IPV early interventions appropriate to help prevent adverse mental health outcomes later in life [29].

\section{Limitations of the study}

The current paper has several limitations. The paper relies on data that were self-reported and is therefore prone to recall and social desirability bias, which may lead to under reporting, especially when dealing with such a sensitive subject. The fact that few people responded to the question on IPV in such a large survey could have also introduced selection bias. Even though age group (15-19/20-24) is controlled for in adjusted models factors assessed are likely affected by the age of the AGYW, unfortunately, the small sample size would not allow for further stratification. The survey instrument on IPV was limited to a few items and did not utilise the highly recommended WHO five item scale on IPV since focus was mainly on HIV and sexual health. The study could also be limited by unmeasured important covariates such as childhood traumas, which are typically predictive of IPV experience. Including gender norms or male controlling behaviours again known risk factors for IPV experience that capture social aspects of gender inequalities. In addition, due to its crosssectional nature, the study can only demonstrate an association and cannot infer any causality about IPV. The small sub-sample may have an impact on the precision of the estimates especially given the wide confidence intervals for some of the results. Furthermore, stepwise multiple regression include bias in parameter estimation, inconsistencies among model selection algorithms, and an inappropriate focus or reliance on a single best model. We discuss each of these issues with examples. Future, surveys with larger sample sizes would allow for more robust model fitting. Nevertheless, this paper was based on a nationally representative sample that can be used to draw inference about factors associated with lifetime physical IPV experiences among AGYW in the country.

\section{Conclusion}

This paper presents the first nationwide secondary data analysis of lifetime physical IPV experiences among AGYW in South Africa. The findings highlight the need for targeted structural interventions in low SES 
households especially in urban areas. This suggests a need or social interventions to deal with powerful social and economic forces that encourage males to control female behaviour and trap women in abusive relationships. Women's economic empowerment strategies have been proposed as means to reduce women's risk of physical and sexual abuse [34]. This should be coupled with changing social and cultural norms that support violence against women, and challenging gender roles that grant men authority over women through awareness and advocacy campaigns. In addition, the findings suggest the urgency of psychosocial support for victims of IPV in the identified setting. Furthermore, the findings suggest the urgency of developing strategic parental-centred interventions that teach parents how to improve the safety of their young women, while simultaneously imparting skills that could facilitate a greater and lasting resilience among young IPV victims/survivors. Finally, there is a need for nationally representative survey specific on IPV and other forms gender-based violence in order to guide policy and design more nuanced and targeted IPV interventions in the country.

\section{Acknowledgements}

We would like to thank all study participants and the Human Sciences Research Council project team.

\section{Authors' contributions}

Jacqueline Mthembu conceptualised the study. Musawenkosi Mabaso performed the statistical analysis. Jacqueline Mthembu and Musawenkosi Mabaso drafted of the manuscript. Sarah Reis, Khangelani Zuma and Nompumelelo Zungu made substantial intellectual input. All authors contributed to the review of draft manuscript and approved the final manuscript.

\section{Funding}

This manuscript was supported by the President's Emergency Plan for AIDS Relief (PEPFAR) through the Centers for Disease Control and Prevention, under the terms of Cooperative Agreement Number NU2GGH001629.

\section{Availability of data and materials}

The datasets used and/or analysed during the current study are available from the corresponding author on reasonable request.

\section{Declarations}

\section{Ethics approval and consent to participate}

The survey protocol was approved by the HSRC Research Ethics Committee (REC: 4/18/11/15), and the Associate Director for Science, Center for Global Health, Centers for Disease Control and Prevention (CDC). Each participant signed an informed consent form prior to participating in the study. Participants' privacy and confidentiality was protected through unique individual identifiers. This also included the use of linked anonymous blood testing with informed consent. All data collections methods were carried out in accordance with the relevant guidelines and regulations stipulated by the two research ethics bodies from which approval were received.

\section{Consent for publication}

Not applicable.

\section{Competing interests}

The authors declare that they have no competing interests.

\section{Author details}

Human and Social Capabilities Division, Human Sciences Research Council, Pretoria, South Africa. ${ }^{2}$ University of California, Los Angeles, USA. ${ }^{3}$ Human and Social Capabilities Division, Human Sciences Research Council, Durban, South Africa. ${ }^{4}$ United Nations Population Fund, Pretoria, South Africa. ${ }^{5}$ School of Public Health, University of Witwatersrand, Johannesburg, South Africa.

${ }^{6}$ Department of Psychology, University of Pretoria, Pretoria, South Africa.

Received: 31 December 2020 Accepted: 1 June 2021

Published online: 16 June 2021

\section{References}

1. World Health Organization. Violence against women: a 'global health problem of epidemic proportions. Geneva: World Health Organization; 2013.

2. Stöckl H, March L, Pallitto C, Garcia-Moreno C. Intimate partner violence among adolescents and young women: prevalence and associated factors in nine countries: a cross-sectional study. BMC Public Health. 2014;14(1):751. https://doi.org/10.1186/1471-2458-14-751.

3. Global W. Regional estimates of violence against women: prevalence and health effects of intimate partner violence and non-partner sexual violence. Geneva: World Health Organization; 2013.

4. StatsSA. Mid-year population estimates 2017. Pretoria: Statistics South Africa; 2017.

5. Selin A, DeLong SM, Julien A, MacPhail C, Twine R, Hughes JP, et al. Prevalence and associations, by age group, of IPV among AGYW in rural South Africa. SAGE Open. 2019;9(1):215824401983001. https://doi.org/10.11 77/2158244019830016

6. Norman R, Schneider M, Bradshaw D, Jewkes R, Abrahams N, Matzopoulos $\mathrm{R}$, et al. Interpersonal violence: an important risk factor for disease and injury in South Africa. Popul Health Metrics. 2010;8(1):32. https://doi.org/1 0.1186/1478-7954-8-32.

7. Jewkes R, Morrell R. Gender and sexuality: emerging perspectives from the heterosexual epidemic in South Africa and implications for HIV risk and prevention. J Int AIDS Soc. 2010;13(1):6. https://doi.org/10.1186/1758-2 652-13-6.

8. Devries KM, Mak J, Bacchus LJ, Child JC, Falder G, et al. Intimate partner violence and incident depressive symptoms and suicide attempts: a systematic review of longitudinal studies. PLoS Med. 2013;10(5):e1001439.

9. World Health Organization. Violence against women: Intimate partner and sexual violence against women (Fact sheet No. 239). Geneva: World Health Organization; 2014.

10. Taillieu TL, Brownridge DA. Violence against pregnant women: prevalence, patterns, risk factors, theories, and directions for future research. Aggress Violent Behav. 2010;15(1):14-35. https://doi.org/10.1016/j.avb.2009.07.013.

11. Shamu S, Abrahams N, Temmerman M, Musekiwa A, Zarowsky C. A systematic review of African studies on intimate partner violence against pregnant women: prevalence and risk factors. PLoS One. 2011;6(3):e17591. https://doi.org/10.1371/journal.pone.0017591.

12. Shamu S, Abrahams N, Zarowsky C, Shefer T, Temmerman M. Intimate partner violence during pregnancy in Zimbabwe: a cross-sectional study of prevalence, predictors and associations with HIV. Trop Med Int Heal. 2013; 18(6):696-711. https://doi.org/10.1111/tmi.12078.

13. Andersson N, Ho-Foster A, Mitchell S, Scheepers E, Goldstein S. Risk factors for domestic physical violence: national cross-sectional household surveys in eight southern African countries. BMC Womens Health. 2007;7(1):11. https:// doi.org/10.1186/1472-6874-7-11.

14. Jewkes R, Sikweyiya Y, Morrell R, Dunkle K. Gender inequitable masculinity and sexual entitlement inrape perpetration South Africa: findings of a crosssectional study. PLoS One. 2011;6(12):e29590. https://doi.org/10.1371/journal. pone.0029590.

15. Capaldi DM, Knoble NB, Shortt JW, Kim HK. A systematic review of risk factors for intimate PartnerViolence. Partn Abus. 2012;3(2):231-80. https:// doi.org/10.1891/1946-6560.3.2.231.

16. Department of Women, Youth, and Persons with Disabilities. The national response to the Gender Based and Sexual Violence in South Africa, 6 November; 2020. https://www.ojp.gov/ncjrs/virtual-library/abstracts/ violence-against-women-south-africa-state-response-domestic

17. Simbayi LC, Zuma K, Zungu N, Moyo S, Marinda E, Jooste S, et al. South African national HIV prevalence, incidence, behaviour and communication survey, 2017. Cape Town: HSRC Press; 2019. 
18. Booysen F, van der Berg S, Burger R, von Maltitz M. du Rand G. Using an asset index to assess trends in poverty in seven sub-Saharan African countries. World Dev. 2008;36(6):1113-30. https://doi.org/10.1016/j. worlddev.2007.10.008.

19. Saunders JB, Aasland OG, Babor TF, De La Fuente JR, Grant M. Development of the alcohol use disorders identification test (AUDIT): WHO collaborative project on early detection of persons with harmful alcohol consumption-II. Addiction. 1993;88(6):791-804. https://doi.org/10.1111/j.1360-0443.1993.tb02 093.x.

20. Morojele NK, Nkosi S, Kekwaletswe CT, Shuper PA, Manda SO, Myers B, et al. Utility of brief versions of the alcohol use disorders identification test (AUDIT) to identify excessive drinking among patients in HIV Care in South Africa. J Stud Alcohol Drugs. 2016;78(1):88-96.

21. Kessler RC, Andrews G, Colpe L, Hiripi E, Mroczek DK, Normand SLT, et al. Short screening scales to monitor population prevalences and trends in non-specific psychological distress. Psychol Med. 2001;32(6):959-76.

22. Fox GL, Benson ML. Household and neighbourhood contexts of intimate partner violence. Public Health Rep. 2006;121(4):419-27. https://doi.org/1 $0.1177 / 003335490612100410$.

23. Pinchevsky GM, Wright EM. The impact of neighborhoods on intimate partner violence and victimization. Trauma Violence Abuse. 2012;3:112-32.

24. Oduro GY, Swartz S, Arnot M. Gender-based violence: Young women's experiences in the slums and streets of three sub-Saharan african cities. Theor Res Edu. 2012;10(3):275-94. https://doi.org/10.1177/14778785124593 95.

25. Misganaw AC, Worku YA. Assessment of sexual violence among street females in Bahir-Dar town, North West Ethiopia: A mixed method study. BMC Public Health. 2013;13:825.

26. Pandey GK, Dutt D, Banerjee B. Partner and relationship factors in domestic violence: perspectives of women from a slum in Calcutta, India. J Interpers Violence. 2009;24(7):1175-91. https://doi.org/10.1177/0886260508322186.

27. Mannell J, Seyed-Raeisy I, Burgess R, Campbell C. The implications of community responses to intimate partner violence in Rwanda. PLoS One. 2018;13(5):e0196584. https://doi.org/10.1371/journal.pone.0196584.

28. Keynejad RC, Hanlon C, Howard LM. Psychological interventions for common mental disorders in women experiencing intimate partner violence in low-income and middle-income countries: a systematic review and meta-analysis. Lancet Psychiatry. 2020;7(2):173-90. https://doi.org/10.101 6/S2215-0366(19)30510-3.

29. Young-Wolff KC, McCaw B. Intimate partner violence and psychological distress: opportunities for prevention and early intervention among emerging adult women. J Women's Health (Larchmt). 2019;28(8):1013-4. https://doi.org/10.1089/jwh.2019.7918.

30. Pigeon WR, Cerulli CJD, Richards HMS, He H, Perlis M, Caine E. Sleep disturbances and their association with mental health among women exposed to intimate partner violence. J Women's Health. 2011;20(12):19239. https://doi.org/10.1089/jwh.2011.2781

31. Miller E, Tancredi DJ, Decker MR, McCauley HL, Jones KA, Anderson $\mathrm{H}$, et al. A family planning clinic-based intervention to address reproductive coercion: a cluster randomized controlled trial. Contraception. 2016;94(1): 58-67. https://doi.org/10.1016/j.contraception.2016.02.009

32. Miller E, Decker MR, McCauley HL, et al. A family planning clinic partner violence intervention to reduce risk associated with reproductive coercion. Contraception. 2011;83(3):274-80. https://doi.org/10.1016/j.contraception.201 0.07.013.

33. Miller E, Goldstein S, McCauley HL, et al. A school health center intervention for abusive adolescent relationships: a cluster RCT. Pediatrics. 2015;135(1): 76-85. https://doi.org/10.1542/peds.2014-2471

34. Abramsky T, Lees S, Stöckl H, Harvey S, Kapinga I, Ranganathan M, et al. Women's income and risk of intimate partner violence: secondary findings from the MAISHA cluster randomised trial in North-Western Tanzania. BMC Public Health. 2019;19(1):1108. https://doi.org/10.1186/s12889-019-7454-1.

\section{Publisher's Note}

Springer Nature remains neutral with regard to jurisdictional claims in published maps and institutional affiliations.

\section{Ready to submit your research? Choose BMC and benefit from:}

- fast, convenient online submission

- thorough peer review by experienced researchers in your field

- rapid publication on acceptance

- support for research data, including large and complex data types

- gold Open Access which fosters wider collaboration and increased citations

- maximum visibility for your research: over $100 \mathrm{M}$ website views per year

At BMC, research is always in progress.

Learn more biomedcentral.com/submissions 